\section{Instituto Materno Infantil de Pernambuco \\ (IMIP) inicia capacitação de agentes \\ (IMIP) inicia capacitação de agentes
comunitários de saúde na estratégia AIDPI}

\section{The Instituto Materno Infantil de Pernambuco (IMIP) implements training for community health agents as part of the IMCI strategy

The Instituto Materno Infantil de
Pernambuco (IMIP) implements training for
community health agents as part of the IMCI
strategy

A Atenção Integrada às Doenças Prevalentes da Infância (AIDPI) ao apresentar um novo enfoque de abordagem à saúde da criança no primeiro nível da assistência, permite avaliar de maneira sistemática os principais fatores que afetam a saúde dos menores de cinco anos de idade, ao promover a identificação de sinais e sintomas de forma precoce, favorecendo, ainda, a integração de ações curativas com medidas de prevenção e promoção da saúde. "A estratégia introduz o conceito de integralidade, surgindo como alternativa para aplicar os programas de controle específicos já existentes (IRA, Diarréia, Crescimento e Desenvolvimento, Imunização, etc.), englobando os principais problemas de saúde que afetam as crianças menores de cinco anos de idade, afecções geralmente preveníveis ou facilmente tratáveis, mediante a aplicação de tecnologias apropriadas e de baixo custo" (Felisberto et al., 2000: 27). 1

O Ministério da Saúde do Brasil (MS), adotou a estratégia em 1995 e a partir de 1996 deu início à adaptação do material instrucional que permitiu nos anos seguintes a capacitação de milhares de profissionais médicos e enfermeiros por todo o país. Desde então a estratégia AIDPI vem sendo implantada entre as ações desenvolvidas pelas equipes do Programa de Saúde da Família, enfermeiros do Programa de Agentes Comunitários de Saúde (PACS) e pelos profissionais das Unidades Básicas de Saúde. ${ }^{2}$

A ampliação da resolução no nível básico de atenção tendo em vista o aumento da participação da comunidade na resolução dos problemas de saúde das crianças, entretanto, está condicionada a uma efetiva participação dos Agentes Comunitários de Saúde (ACS), nesse processo. São esses agentes que
Instituto Materno Infantil de Pernambuco. Programa de Extensão Comunitária. 1

${ }^{1}$ Rua dos Coelhos, 300. Recife, PE, Brasil. CEP 50.070-550. E mail: www.imip.org.br viabilizarão, de fato, a possibilidade de se fazer, na Atenção Básica à Saúde, o seguimento de grande contingente de crianças na comunidade facilitando o acesso ao acompanhamento de sua situação de saúde, proporcionando inclusive a redução das oportunidades perdidas e favorecendo a mudança da abordagem individual e de ações isoladas, para uma abordagem integrada.

Dentre os objetivos específicos da AIDPI, dois se destacam pela aproximação com as atividades desenvolvidas pelos ACS. 3

Introduzir aspectos de promoção e prevenção de saúde infantil na rotina de atenção dos serviços de saúde;

Expandir a atenção integrada ao nível comunitário.

No ano 2000 o Ministério da Saúde do Brasil firmou convênio com o Instituto Materno Infantil de Pernambuco (IMIP) com o objetivo de viabilizar a adaptação do material teórico da estratégia da Atenção Integrada às Doenças Prevalentes da Infância (AIDPI) para o Agente Comunitário de Saúde (ACS). O trabalho que envolveu profissionais ligados ao Programa de Extensão Comunitária do IMIP (PEC/IMIP), consultores e técnicos do MS foi concluído com êxito e, no início de 2002, começaram a ser distribuídos com os ACS, em todo o país, os livros "Atenção Básica à Saúde da Criança: texto de apoio para o Agente Comunitário de Saúde" e o "Manual de condutas para Agentes Comunitários de Saúde (AIDPI)".4,5

A experiência acumulada pela instituição e o aprimoramento das atividades de atenção básica em saúde desenvolvidas no PEC/IMIP permitiram que durante os meses de julho e agosto de 2002, fossem capacitados 107 ACS e 19 Auxiliares de Enfermagem que desenvolvem suas atividades em 19 
equipes do Programa Saúde da Família (PSF), e integram o referido programa de extensão, fruto de uma parceria com os municípios de Recife e Olinda no estado de Pernambuco.

Este treinamento permitiu o desenvolvimento de uma metodologia pedagógica que está sendo repassada para os gestores do Sistema Único de Saúde. Ainda, em decorrência da qualidade da capacitação oferecida, os municípios citados tiveram a totalidade de seus enfermeiros (cerca de 120) que já possuíam a formação em AIDPI, capacitados pedagogicamente para a preparação de seus Agentes Comunitários.

\section{Métodos}

Inicialmente houve uma fase de planejamento e desenvolvimento de um método preliminar de treinamento envolvendo duas médicas pediatras facilitadoras da estratégia AIDPI e preceptoras do Programa de Extensão Comunitária, e duas enfermeiras capacitadas em AIDPI. Em seguida, os enfermeiros das equipes de saúde da família integrantes do PEC/IMIP foram sendo capacitados separadamente por estas profissionais, e após este momento, os agentes comunitários e auxiliares de enfermagem de sua área de abrangência eram capacitados em grupos não superiores a 15 agentes, tendo como docentes seus enfermeiros supervisores que trabalhavam em duplas e sob supervisão direta dos preceptores do PEC/IMIP. Dessa forma foram capacitados os 19 enfermeiros, 107 ACS e 19 auxiliares de enfermagem. Isto permitiu que o aperfeiçoamento do método, a cada treinamento, não só quanto à formação do ACS, mas também para a capacitação pedagógica dos enfermeiros, uma vez que o objetivo final era franquear aos gestores municipais uma metodologia de capacitação que pudesse ser adaptada à realidade de cada local.

O passo seguinte seria experimentar o método desenhado para a capacitação pedagógica de grupos de enfermeiros. Ofereceu-se, então, aos municípios de Recife e Olinda a possibilidade de se capacitar os enfermeiros de outras equipes do PSF que não integram o PEC/IMIP e instrutores supervisores do Programa de Agentes Comunitários de Saúde (PACS). Assim, os treinamentos aconteceram para grupos de, em média, 20 enfermeiros, tendo como docentes uma das médicas pediatras preceptora do PEC/IMIP e uma enfermeira de uma de suas unidades de saúde. Foram ao todo seis grupos que possibilitaram, também, a partir da interação com a experiência de cada um dos profissionais, o aprimoramento do método desenvolvido.
Sugere-se, assim, que a capacitação pedagógica dos enfermeiros deverá ser realizada em oito horas, num mesmo dia, em turmas não superiores a 20 treinandos, e a capacitação dos agentes comunitários de saúde em 20 horas, sendo cinco tardes, levandose em consideração o benefício para a comunidade em não se retirar os mesmos de suas áreas durante todo o dia e, em turmas que reunam, no máximo, o equivalente aos ACS supervisionados por dois enfermeiros. Sugere-se que os auxiliares de enfermagem das unidades do PSF sejam também treinados, tendo em vista a relação profissional dos mesmos com a comunidade usuária dos serviços.

Durante todo o treinamento, aspectos fundamentais devem ser perseguidos pelo Instrutor/Supervisor:

Ensinar. Certificar-se de que cada ACS entendeu como manusear os instrumentos didáticos e os seus conteúdos; explicar qualquer informação que o ACS não compreendeu, repetir quantas vezes for necessário;

Motivar. O ACS, parabenizando-o quando dos acertos e estimulando-o nas dificuldades;

Administrar. Fazer um planejamento do curso com antecedência, organizar todo o material e equipamentos necessários. Garantir que o transporte da sala de aula para o serviço de saúde e o seu regresso (quando necessário) seja eficiente, durante as aulas práticas.

O Instrutor/Supervisor deverá deixar claro aos ACS, que a partir deste treinamento, eles passarão a utilizar o "Manual de Condutas", de modo rotineiro, durante suas visitas domiciliares no atendimento à criança menor de cinco anos. E, lembrar que não precisam e não devem decorar as classificações e condutas, e sim, sempre ler e seguir a sistematização do atendimento pelo manual de condutas.

O Instrutor/Supervisor deverá estabelecer um protocolo de agendamento para o controle dos bebês e crianças com classificações que necessitem de consulta de retorno, para que os ACS não esqueçam e não prejudique o acompanhamento do bebê e da criança, além de não causar danos na credibilidade dos ACS em relação a expectativa da mãe ou responsável.

Esta metodologia pedagógica está sendo colocada à disposição dos gestores do Sistema Único de Saúde em todo o país, por intermédio de seu site na internet (www.imip.org.br). O material intitulado "Curso de Capacitação para Agentes Comunitários de Saúde: Guia de Treinamento para Instrutores/Supervisores do PACS/PSF" está disponível para download e impressão, podendo, assim, favorecer o processo de implantação da estratégia AIDPI no Brasil. É importante, entretanto, destacar a necessi- 
dade de aperfeiçoamento que com certeza se fará necessária, uma vez que o objetivo desta iniciativa é franquear aos gestores municipais uma metodologia

\section{Referências}

1.Felisberto E, Carvalho EF, Samico I. Estratégia da atenção integrada às doenças prevalentes da infância (AIDPI) considerações sobre o processo de implantação. Rev IMIP 2000; 24: 24-31.

2.Ministério da Saúde. Secretaria de Políticas de Saúde. Área da Saúde da Criança. Programas e Projetos da Saúde da Criança: responsabilidade compartilhadas em benefício das crianças brasileiras. Rev Bras Saúde Matern Infant 2002; 2: 193-6.

3.Benguigui Y. Integrated Management of Childhood Illness (IMCI)]: na innovative vision for child health care. Rev Bras Saúde Matern Infant 2002; 1: 223-36. de capacitação que possa ser adaptada à realidade de cada local.
4.Ministério da Saúde. Secretaria de Políticas de Saúde. Departamento de Atenção Básica, IMIP (Instituto Materno Infantil de Pernambuco). Atenção básica à saúde da criança: texto de apoio para o agente comunitário de saúde; Atenção Integrada às Doenças Prevalentes na Infância (AIDPI). Brasília, DF: Ministério da Saúde; 2001.

5.Ministério da Saúde. Secretaria de Políticas de Saúde. Departamento de Atenção Básica, IMIP (Instituto Materno Infantil de Pernambuco). Manual de condutas para agentes comunitários de saúde: Atenção Integrada às Doenças Prevalentes na Infância (AIDPI). Brasília, DF: Ministério da Saúde; 2001. 